\title{
THE POLISH ADAPTATION AND FURTHER VALIDATION OF THE COVID STRESS SCALES (CSS)
}

\author{
Monika Frydrychowicz, Julia Pradelok, Kinga Zawada, Dominika Zyśk, \\ \& Katarzyna Adamczyk \\ Faculty of Psychology and Cognitive Science, Adam Mickiewicz University in Poznań (Poland)
}

\begin{abstract}
The scientific need to recognize the impact of the COVID-19 pandemic on human psychosocial functioning requires reliable and valid research tools to assess this impact. Therefore, we designed a study to create and further validate a Polish version of a research instrument assessing stress, anxiety, and fear related to the pandemic - the COVID Stress Scales (CSS; Taylor et al., 2020). This paper presents the specific research steps designed to develop and validate the Polish-language version of CSS (Taylor et al., 2020). These steps are as follows: 1) the translation of the original CSS into the Polish language by three independent translators and the back-translation by three other independent translators; 2) the assessment of the equivalence of the Polish translation of CSS in a study involving a sample of 30-60 bilingual people, fluent both in English and Polish languages; 3) the pilot study employing the pre-final Polish version of CSS; 4) the validation study involving a sample 600-900 participants in which the following instruments will be used: the Fear of COVID-19 Scale, the Patient Health Questionnaire-9 Scale, the Short Health Anxiety Inventory, the Social Desirability Scale, the Obsessive-Compulsive Inventory-Revised Scale, the Xenophobia subscale of the Questionnaire of Political Beliefs and the subscale Sensation seeking from the Impulsive Behavior Scale.

We expect that the Polish version of CSS will be widely used by Polish researchers in their studies concerning the impact of the COVID-19 pandemic and other epidemiological threats on mental health. At the same time, we hope that our study will provide results that will help foreign researchers understand the COVID-19 pandemic in other countries.
\end{abstract}

Keywords: COVID-19, coronavirus, the COVID Stress Scales, stress, anxiety, fear.

\section{Introduction}

According to the World Health Organization's data, on January 5, 2021, over 84 million coronavirus cases have been confirmed, and 1.8 million deaths have been reported worldwide, and pandemic spreads to all countries of the world. Poland, where the presented project proposal is intended to be implemented, has reported over 1.3 million cases and over 29 thousand deaths.

In response to the need of recognizing how people feel when an epidemic or a pandemic situation occurs (such as H1N1 in 2009 or the SARS outbreak) and currently the COVID-19 pandemic, Taylor and colleagues in the 2020 year created an instrument to measure stress, anxiety, and fear related to the COVID-19 pandemic, i.e., the COVID Stress Scales (CSS). This instrument was designed in such a manner that would allow researchers to adapt CSS in the assessment of future pandemics.

The CSS was developed and initially validated in population-representative samples from Canada $(\mathrm{N}=3479)$ and the United States $(\mathrm{N}=3375)$. The study was conducted during the early stages of the pandemic in the United States and Canada when many people experienced emotional distress.

Previous research by one of the authors of CSS - Taylor (2019) - suggested that when people face a pandemic mostly fear becoming infected, coming into contact with contaminated objects or surfaces, foreigners who may be infected, and the socio-economic consequences of the pandemic (Taylor, 2020). People may also present compulsive and reassurance seeking behaviors and symptoms of traumatic stress (Taylor 2019).

In the original study, CSS was correlated with the following research instruments:

1. Patient Health Questionnaire-4 (PHQ-4; Kroenke et al., 2009) which measures current anxiety and depression; 
2. Short Health Anxiety Inventory (SHAI; Salkovskis et al., 2002) only the main subscale was used which measures health anxiety independently of physical health status;

3. Obsessive-Compulsive Inventory-Revised (OCI-R; Foa et al., 2002) which measures symptoms of obsessive-compulsive disorder (OCD);

4. Xenophobia Scale (XS; van Zalk et al., 2013) which measures negative attitudes towards immigrants;

5. Marlowe Crowne Social Desirability Scale Short Form (MCSD-SF; Reynolds, 1982) which measures the tendency to respond in socially desirable ways.

The performed analyses revealed that CSS consists of five scales that measure symptoms of stress and anxiety caused by COVID-19: 1) Danger and contamination fears; 2) Fears about economic consequences; 3) Xenophobia; 4) Compulsive checking and reassurance seeking and 5) Traumatic stress symptoms about COVID-19.

In the original study, all the correlations between the CSS subscales and the pre- COVID trait measures of health anxiety and obsessive-compulsive (OC) contamination and checking symptoms were significant; the correlations between the five CSS subscales and social desirability were statistically significant. Further, all the CSS subscales were intercorrelated.

The authors of CSS recommend using their instrument to identify people in need of mental health services and predict which people are most likely to engage in safety behaviors. They also pointed out the need to include structured diagnostic assessments (i.e., DSM-5 or ICD-11 diagnoses) in future research, which would have been useful in evaluating criterion-related (known-groups) validity of the CSS.

In Poland, there is a deficit to assess stress, anxiety, and fear related to COVID-19. Therefore, the research performed by Taylor and colleagues (2020) encouraged us to design an investigation aimed at developing and validating the Polish version of the COVID Stress Scales (CSS).

The Polish version of the CSS scale will enable researchers to investigate the impact of the COVID-19 pandemic on Polish women and men's stress and anxiety. Due to the lack of standardized tools, such research is more challenging to be performed. Moreover, as the original CSS, the Polish version of CSS will also allow researchers to investigate the COVID-19 pandemic and other epidemiological threats.

In subsequent parts of the paper, we will present the specific research steps to develop and validate the Polish version of CSS.

\section{Method}

The designed research will be conducted according to the standards and recommendations for research aimed at cultural adaptation of research tools and their validation (e.g., Brzeziński \& Hornowska, 2007). The study will consist of the following four steps:

\section{Step 1: Translation}

The translation procedure will involve translating the original CSS in the English language into the Polish language by three independent translators and the back-translation of the Polish experimental version of the CSS Scale into English by the other three independent translators.

\section{Step 2: The equivalence of the Polish version of CSS}

The Polish version of CSS's equivalence will be assessed in a study in which 30-60 bilingual participants will be enrolled.

\section{Step 3: Pilot study}

The pilot study with a pre-final Polish version of CSS will involve 60 participants.

\section{Step 4: Final validation study with two measurements}

The final validation study will involve two measurements to assess the stability of CSS scores in time.

In the first measurement, we predict that about 300-500 will take part, whereas in the second measurement, four weeks after the first measurement, around 250-450 participants will take part.

In order to avoid the excessive burden of our participants, the validation study will be divided into three separate studies employing randomized packages of research instruments. 


\section{Measures}

The selection of tools in this study was determined by the desire to extend knowledge on the Polish version of CSS's validity.

The plan to use other tools, i.e., the Fear of COVID-19 Scale (FCV-19S; Ahorsu et al., 2020), was based on the CSS scale's future directions authors. Specifically, the authors of the CSS scale indicated that in further research, it would be essential to use tools that also measure fears related to the COVID-19 pandemic, such as the Fear of COVID-19 Scale (FCV-19S; Ahorsui in, 2020) that was not available during the research by Taylor and colleagues (2020).

Further, the Sensation seeking subscale that is a part of the Impulsive Behavior Scale (Lynam et al. 2007) will be used to extend an assessment of the discriminant validity of the CSS.

Finally, due to the lack of Polish adaptations of three scales that were used in the original study, the following instruments will be replaced in this investigation: PHQ-4, MCSD-SF and XS, The PHQ-4 scale by the PHQ-9 scale, the Marlowe Crowne Social Desirability Scale Short Form (MCSD-SF; Reynolds, 1982) by the Social Desirability Scale (SDS-17; Stöber, 2001), and the Xenophobia Scale (XS; van Zalk et al., 2013) by the Xenophobia subscale of the Questionnaire of Political Beliefs (Czarnek et al., 2017).

As a result, in the designed study, the following tools will be used:

The COVID Stress Scales (CSS; Taylor et al., 2020). This tool measures stress related to the COVID-19 pandemic, and it is the subject of our adaptation and validation. It consisted of 36 items that are rated using a 4-point Likert scale from 0 (not at all) to 4 (extremely) and from 0 (never) to 4 (almost always).

The Fear of COVID-19 Scale (FCV-19S; Ahorsu et al., 2020). This instrument measures the fear associated with the COVID-19 pandemic. In this study, we will use our Polish translation of FCV-19S. The scale consists of 7 items, to which the examined person responds on a 5-point Likert scale from 1 (definitely disagree) to 5 (definitely agree). The authors of this project proposal will translate the scale.

The Patient Health Questionnaire-9 (PHQ-9; Kroenke et al., 2001) (Polish translation - MAPI Research Institute). This questionnaire measures anxiety and depression. It includes nine items rated on a 4-point Likert scale from 1 (not annoying at all) to 4 (almost daily).

The Short Health Anxiety Inventory (SHAI; Salkovskis et al., 2002) (Polish adaptation - Kocjan (2016). This tool assesses cognitive factors related to hypochondria. This inventory consists of 18 items rating by choosing answers marked with letters from A to D. The original study includes the subscale measuring health-related anxiety regardless of health status and consists of 14 items. In this study, this subscale will be used.

The Social Desirability Scale (SDS-17; Stöber, 2001) (Polish adaptation - Cieciuch et al. 2013). This scale measures social approval. The scale consists of 16 items rated by choosing the answer true/false.

The Obsessive-Compulsive Inventory-Revised (OCI-R; Foa et al., 2002) (Polish translation Jeśka, 2012). This instrument assesses the symptoms of obsessive-compulsive disorder. The scale consists of 18 items rated on a 5-point scale from 0 (not at all) to 4 (very often). The original study includes two subscales to measure checking and washing. In this study, these two subscales will be used.

The Political Beliefs Questionnaire (Czarnek et al., 2017) is an instrument created by Polish researchers to assess political beliefs. In this study, the Xenophobia subscale (three items) will be used. Respondents rate statements using a 5-point Likert scale from 1 (strongly disagree) to 5 (strongly agree).

The 20-item Impulsive Behavior Scale (UPPS-P; Whiteside \& Lynam, 2001) (Polish adaptation - Poprawa, 2019). In this study, the Sensation Seeking (PD) subscale (four items) will be used. The respondents rate statements using a 4-point Likert scale ranging from 1 (completely agree) to 4 (completely disagree).

Demographic data. Demographic data will include questions concerning age, gender, place of living, education, employment, and experiences related to the COVID-19. 
The assessment of the Polish version of CSS's equivalence, pilot study, and final validation study will be conducted as online research. Access to the survey will be possible through a link sent in the recruitment advertisement through e-mail and a link on social networks.

Gratifications in shopping vouchers to the EMPIK stores are planned for people participating in the research. These gratifications will be awarded in the form of a lottery.

\section{Desired results description}

The adaptation and validation of the CSS scale to Polish conditions will allow researchers in Poland to investigate the impact of the COVID-19 pandemic on stress and anxiety among Poles.

Due to the need for standardized tools in this research area, the Polish adaptation of the CSS will enable the successful performance of such research in Poland.

Furthermore, as the CSS authors emphasized, CSS has been designed to be also employed in research concerning other pandemics (Taylor et al., 2020). Therefore, the Polish adaptation of CSS will enable research on the COVID-19 pandemic and other epidemiological threat situations in Poland.

\section{Acknowledgments}

The presented project proposal is financed in the scope of the Adam Mickiewicz University in Poznań project's "Excellence Initiative - Research University" (Application number 009/34/UAM/0003). The Principal Investigator of the project is Julia Pradelok, a fourth-year psychology student at the Faculty of Psychology and Cognitive Science at Adam Mickiewicz University in Poznań.

The project's supervisor is Katarzyna Adamczyk, Ph.D., Associate Professor at the Faculty of Psychology and Cognitive Science at Adam Mickiewicz University in Poznań.

\section{References}

Ahorsu, D. K., Lin, C. Y., Imani, V., Saffari, M., Griffiths, M. D., \& Pakpour, A. H. (2020). The Fear of COVID-19 Scale: Development and initial validation. International Journal of Mental Health and Addiction, 1-9. doi: 10.1007/s11469-020-00270-8

Brzeziński, J. \& M., Hornowska, E. (2007). Adaptacja kulturowa testów psychologicznych. [Cultural adaptation of psychological tests]. In J. Strelau (Ed.), Psychologia. Podręcznik akademicki. [Psychology. Academic Textbook.] (Vol. 1, pp. 415-426). Gdańsk: GWP.

Cieciuch, J., Davidov, E., Gasiul, H., Strus, W., Rowiński, T., \& Fronczyk, K. (2013, July). Common factor in measurement of values - pure method or social desirability factor? Oral presentation at the 5th Conference of the European Survey Research Association, Lublana, Slovenia.

Czarnek, G., Dragon, P., Szwed, P., \& Wojciszke, B. (2017). Kwestionariusz przekonań politycznych: własności psychometryczne [Political Beliefs Questionnaire: Psychometric properties]. Psychologia Społeczna, 12(2), 205-222. doi: 10.7366/1896180020174108

Foa, E. B., Huppert, J. D., Leiberg, S., Langner, R., Kichic, R., Hajcak, G., \& Salkovskis, P. M. (2002). The Obsessive-Compulsive Inventory: Development and validation of a short version. Psychological Assessment, 14(4), 485. doi: 10.1037/1040-3590.14.4.485

Jeśka, M. (2012). Narzędzie do pomiaru zaburzenia obsesyjno-kompulsyjnego (zastosowanie, właściwości, wady i zalety). [Tools for measuring the symptoms of obsessive - compulsive disorder (application, properties, advantages and disadvantages]. Neuropsychiatria. Przeglad Kliniczny. [Review of Clinical Neuropsychiatry.], 4(3), 138-142.

Kocjan, J. (2016). Short Health Anxiety Inventory (SHAI)-Polish version: Evaluation of psychometric properties and factor structure. Archives of Psychiatry and Psychotherapy, 3, 68-78.

Kroenke, K., Spitzer, R. L., \& Williams, J. B. (2001). The PHQ-9: validity of a brief depression severity measure. Journal of General Internal Medicine, 16(9), 606-613. doi: 10.1046/j.15251497.2001.016009606.x

Poprawa, R. (2019). Research on the Polish short version of the Impulsive Behavior Scale UPPS-P. Alcoholism and Drug Addiction/Alkoholizm $i$ Narkomania, 32(1), 35-62. doi:10.5114/ain.2019.85767.

Reynolds, W. M. (1982). Development of reliable and valid short forms of the Marlowe-Crowne Social Desirability Scale. Journal of Clinical Psychology, 38(1), 119-125. doi: 10.1002/10974679(198201)38:1\%3C119::AID-JCLP2270380118\%3E3.0.CO;2-I 
Salkovskis, P. M., Rimes, K. A., \& Warwick, H. M. C. (2002). The Health Anxiety Inventory: Development and validation of scales for the measurement of health anxiety and hypochondriasis. Psychological Medicine, 32(5), 843. doi: 10.1017/S0033291702005822

Stöber, J. (2001). The Social Desirability Scale-17 (SDS-17): Convergent validity, discriminant validity, and relationship with age. European Journal of Psychological Assessment, 17(3), 2001, 222-232. doi: 10.1027//1015-5759.17.3.222

Taylor, S. (2019). The psychology of pandemics: Preparing for the next global outbreak of infectious disease. Newcastle upon Tyne, UK: Cambridge Scholars Publishing.

Taylor, S., Landry, C., Paluszek, M., Fergus, T. A., McKay, D. \& Asmundson, G. J. (2020). Development and initial validation of the COVID Stress Scales. Journal of Anxiety Disorders, 72,102232, doi: 10.1016/j.janxdis.2020.10223

van Zalk, M. H. W., Kerr, M., Van Zalk, N., \& Stattin, H. (2013). Xenophobia and tolerance toward immigrants in adolescence: Cross-influence processes within friendships. Journal of Abnormal Child Psychology, 41(4), 627-639. doi: 10.1007/s10802-012-9694-8

Whiteside, S. P., \& Lynam, D. R. (2001). The five factor model and impulsivity: Using a structural model of personality to understand impulsivity. Personality and Individual Differences, 30(4), 669-689. doi: 10.1016/S0191-8869(00)00064-7 